\title{
MANEJO DOS FERTILIZANTES FOSFATADOS E POTÁsSiCOS EM ARROZ IRRIGADO NO SISTEMA PRÉ-GERMINADO ( ${ }^{1}$ )
}

\author{
ENIO MARCHEZAN $\left(2^{*}\right)$; EDINALVO RABAIOLI CAMARGO $\left({ }^{2}\right)$; TOMMI SEGABINAZZI $\left({ }^{3}\right)$
}

\begin{abstract}
RESUMO
No sistema pré-germinado de cultivo de arroz irrigado, em função da drenagem inicial, as perdas de nutrientes podem ser significativas, dependendo do manejo da adubação adotado, podendo afetar o ambiente e a sustentabilidade do sistema. Nas safras agrícolas de 2000/2001 a 2003/2004 foram desenvolvidos experimentos na Universidade Federal de Santa Maria, com o objetivo de avaliar métodos de adubação fosfatada e potássica na perda de nutrientes na drenagem inicial e na produtividade do arroz irrigado no sistema pré-germinado de cultivo. Os tratamentos foram compostos por sete manejos da adubação fosfatada e potássica, combinando época de aplicação e incorporação ou não dos fertilizantes. As concentrações de fósforo e nitrogênio medidas na água da drenagem inicial não foram influenciadas pelo momento e modo de aplicação dos fertilizantes, sendo quantificado na média dos quatro anos de estudo, em níveis de 0,07 e $0,81 \mathrm{mg} \mathrm{L}^{-1}$ de fósforo e nitrogênio respectivamente. No entanto, para potássio, observa-se que menor quantidade foi carreada juntamente com a água da drenagem inicial, naqueles tratamentos cuja adubação de base foi realizada aos 10 e 30 dias após a semeadura, bem como no tratamento-testemunha. Os manejos de adubação testados, não influenciaram os parâmetros agronômicos avaliados na cultura do arroz irrigado. A produtividade do arroz irrigado não é influenciada pelo momento e modo de realização da adubação fosfatada e potássica, porém se não for mantida lâmina contínua de água a aplicação de fósforo e potássio deve ser executada após a drenagem inicial, a fim de reduzir as perdas de potássio.
\end{abstract}

Palavras-chave: adubação, drenagem inicial, Oryza sativa L., perda de nutrientes, várzea

\section{ABSTRACT \\ PHOSPHATE AND POTASSIUM FERTILIZATION MANAGEMENT IN PRE-GERMINATED RICE SYSTEM}

In pregerminated rice system, initial water drainage promotes nutrient losses, depending on fertilizer management, leading to environmental problems. During the 2000/01 and 2003/04 growing seasons experiments were conducted at Universidade Federal de Santa Maria aiming to evaluate the effect of phosphorus and potassium fertilizer application methods on nutrient losses and pregerminated rice grain yield. The treatments were seven phosphorus and potassium fertilization methods combining application time and incorporated or not incorporated. Phosphorus and nitrogen concentration measured at initial water drainage were not affected by time or method of fertilizer application. The average of phosphorus and nitrogen were 0.07 and $0.81 \mathrm{mg} \mathrm{L}^{-1}$ respectively. However, less potassium runoff was verified in the treatments where the fertilizer was applied 10 and 30 days after sowing as well as on the check treatment. The treatments tested did not affect the rice agronomic traits. Rice yield was not affected by the phosphorus and potassium fertilization timing and method of application, but when the permanent flooding is not kept on the phosphorus and potassium application need to be done after the initial drainage to reduce potassium losses.

Key words: fertilizer, initial drainage, Oryza sativa L., nutrients loss, lowland.

$\left({ }^{1}\right)$ Recebido para publicação em 8 de fevereiro de 2006 e aceito em 21 de novembro de 2006.

$\left(^{2}\right)$ Universidade Federal de Santa Maria, Centro de Ciências Rurais, Departamento de Fitotecnia, Prédio 44, Sala 5335, $97105-970$ Santa Maria (RS). E-mail: emarch@ccr.ufsm.br $\left(^{*}\right)$ Autor correspondente; nalvo@mail.ufsm.br. Bolsistas do Conselho Nacional e Desenvolvimento Científico e Tecnológico (CNPq).

$\left({ }^{3}\right)$ Rua Souza Júnior, 672, Bairro Mecejana, Boa Vista (RR). 69304-552. E-mail: t_segabinazzi@yahoo.com.br. 


\section{INTRODUÇÃO}

No sistema pré-germinado de cultivo de arroz, o solo é mantido com lâmina de água por cerca de 20 dias antes da semeadura, realizada com sementes prégerminadas sobre essa lâmina. A inundação promove alterações químicas e biológicas que resultam, entre outras transformações, no aumento da disponibilidade de nutrientes na solução do solo (HernÁndez e MEURER, 2000; SiLva et al., 2003). Nesse período, realiza-se a aplicação de fertilizantes fosfatados e potássicos, incorporando-os ou apenas distribuindo-os sobre o solo após o nivelamento.

No entanto, a maior disponibilidade de nutrientes na solução do solo, resultante das reações de oxiredução na área inundada e, sobretudo, oriundas da aplicação dos fertilizantes antes da semeadura, pode induzir à perda de fertilidade do sistema, em função do manejo de drenagem inicial adotado, visando ao melhor estabelecimento das plântulas. Fatores como lixiviação (Beltrame et al., 1992), ausência de plântulas de arroz (SiLva et al., 2003), escorrimento superficial e situações de extravasamento da água dos quadros em condições de precipitações pluviais elevadas, podem influenciar na manutenção dos nutrientes na área.

Em trabalho realizado por MARCHEZAN et al. (2002), visando quantificar as perdas de nutrientes decorrentes da drenagem inicial no sistema prégerminado, observa-se carreamento juntamente com a água drenada de quantidades correspondentes a 3,78; 0,1 e $4,83 \mathrm{~kg} \mathrm{ha}^{-1}$, respectivamente, para N, P e K. No entanto, WEBER et al. (2003), observaram concentrações de nutrientes mais elevadas, ao efetuarem a drenagem inicial dos sistemas pré-germinado, mix de prégerminado e transplante de mudas, as quais, na média dos sistemas, situaram-se em 5,02; 2,06; 10,33 $\mathrm{kg} \mathrm{ha}^{-1}$ para N, P e K. A maior quantidade observada por esses autores, pode ser explicada pelo reduzido intervalo de tempo entre a aplicação dos fertilizantes e a drenagem subseqüente que, nas condições de realização do trabalho, foi de seis dias.

Desta forma, observa-se que as perdas de nutrientes podem ser significativas, dependendo do manejo da adubação e da água utilizados. Essas perdas podem afetar o ambiente através da eutrofização das águas, especialmente quando o nutriente envolvido é o fósforo (SHARPLEY et al., 2000), além de reduzir a fertilidade do solo, comprometendo a sustentabilidade do sistema. No sul da China, Cheung et al. (2003), investigando os níveis de nutrientes e metais pesados na água e sedimentos em rios, detectaram altas concentrações de nutrientes na água, com valores máximos de 10, 22 e 2,9 $\mathrm{mg} \mathrm{L}^{-1}$ para amônio, nitrato e fosfato respectivamente. Na Itália,
DAVIDE et al. (2003), caracterizando a presença de sedimentos e elementos suspensos na água de rio, observaram moderada poluição em todos os locais amostrados, indicando a influência antrópica, decorrentes das atividades urbanas e rurais.

Uma das alternativas que poderia ser adotada para reduzir as perdas de nutrientes é a realização da adubação potássica e fosfatada depois de efetuada a semeadura. Com esse manejo, pode-se minimizar a retirada de nutrientes da área através da drenagem inicial, desde que não ocorra redução da produtividade do arroz.

Assim, este experimento objetivou avaliar o efeito combinado da época de aplicação e da incorporação ou não da adubação fosfatada e potássica na perda de nitrogênio, fósforo e potássio pela drenagem inicial e em parâmetros agronômicos da cultura do arroz irrigado.

\section{MATERIAL E MÉTODOS}

O experimento foi realizado durante quatro safras agrícolas, de 2000/2001 a 2003/2004, em área de várzea sistematizada do Departamento de Fitotecnia da Universidade Federal de Santa Maria, em um Planossolo Hidromórfico eutrófico arênico, com as seguintes características físico-químicas: argila: $270 \mathrm{~g} \mathrm{~kg}^{-1} ; \mathrm{pH}_{\text {agua }}(1: 1): 4,8 ; \mathrm{P}: 8,8 \mathrm{mg} \mathrm{dm}^{-3} ; \mathrm{K}$ : $56 \mathrm{mg} \mathrm{dm}^{-3}$; e M.O.: $22 \mathrm{~g} \mathrm{dm}^{-3}$. As parcelas possuíam $3 \times 4 \mathrm{~m}$, totalizando área útil de $12 \mathrm{~m}^{2}$, sendo individualmente isoladas com taipas. O delineamento experimental utilizado foi o de blocos ao acaso, com quatro repetições e sete tratamentos, listados a seguir: [T1] aplicação dos fertilizantes fosfatados e potássicos 20 dias antes da semeadura (DAS) e incorporação ao solo; [T2] aplicação dos fertilizantes 20 DAS, sem incorporação; [T3] aplicação dos fertilizantes 5 DAS e incorporação ao solo; [T4] aplicação dos fertilizantes 5 DAS, sem incorporação; [T5] aplicação dos fertilizantes a lanço 10 dias após a semeadura; [T6] aplicação dos fertilizantes a lanço 30 dias após a semeadura e T7: testemunha sem aplicação dos fertilizantes potássicos e fosfatados.

Em todas as safras agrícolas, o preparo do solo foi realizado anteriormente à entrada de água. $\mathrm{Na}$ safra de 2000/2001, efetuaram-se gradagens com posterior aplainamento superficial da área e construção de taipas, objetivando isolar as parcelas experimentais. Nos anos subseqüentes, o preparo do solo foi realizado no interior de cada parcela com auxílio de enxada rotativa e aplainamento da superfície do solo. Imediatamente após o preparo do solo executou-se a inundação da área, mantendo-se lâmina de água média de $10 \mathrm{~cm}$, sendo a semeadura 
realizada aos 20 dias após essa operação, com a utilização de $120 \mathrm{~kg} \mathrm{ha}^{-1}$ de sementes da cultivar IRGA 419. A drenagem inicial das parcelas foi efetuada três dias após a semeadura e a irrigação definitiva foi retornada posteriormente em dois dias, sendo a lâmina de água aumentada gradativamente, conforme o desenvolvimento da cultura.

A adubação de base, caracterizada pela aplicação dos fertilizantes potássicos e fosfatados, foi realizada em conformidade com os tratamentos propostos, utilizando-se $40 \mathrm{~kg} \mathrm{ha}^{-1}$ de $\mathrm{P}_{2} \mathrm{O}_{5}$ e $60 \mathrm{~kg}$ ha $^{-1}$ de $\mathrm{K}_{2} \mathrm{O}$, nas formas de superfosfato triplo e cloreto de potássio respectivamente. As quantidades foram aplicadas com base nas recomendações técnicas da cultura para o Sul do Brasil, considerando os critérios de interpretação da análise de solo, onde os teores de fósforo no solo situavam-se na classe alta e os de potássio na classe média. Nos tratamentos com incorporação dos fertilizantes, essa operação foi realizada manualmente com enxada logo após sua aplicação. A adubação nitrogenada foi parcelada em duas aplicações, uma no perfilhamento e outra na diferenciação da panícula, utilizando-se $45 \mathrm{~kg} \mathrm{ha}^{-1}$ de $\mathrm{N}$ na forma de uréia em cada ocasião. Na safra de 2000/2001, o controle de plantas daninhas foi executado pela aplicação de herbicidas pósemergentes: quinclorac, azimsulfuron e metsulfuron, nas dosagens de 375, 5 e $2 \mathrm{~g} \mathrm{ha}^{-1}$ i.a.respectivamente. Nos anos seguintes as plantas daninhas de folhas largas e ciperáceas, foram controladas com os herbicidas azimsulfuron e metsulfuron, nas mesmas dosagens referidas anteriormente.

Por ocasião da drenagem inicial, coletaram-se amostras da água removida em cada unidade experimental, com o objetivo de mensurar as perdas de nitrogênio, fósforo e potássio. A amostragem foi composta por três subamostras, representando a água da superfície, da parte média e da parte inferior da lâmina. As amostras foram acondicionadas em recipientes de vidro (cor âmbar), previamente lavados com solução-limpeza. Na safra de 2002/2003, a determinação dos nutrientes foi realizada pelo Laboratório do Departamento de Química da UFSM, sendo o potássio $\left(\mathrm{K}^{+}\right)$, quantificado por espectrometria de absorção atômica; o fosfato $\left(\mathrm{PO}_{4}{ }^{-3}\right)$ e o nitrato $\left(\mathrm{NO}_{3}{ }^{-}\right.$ ) com cromatografia iônica; e amônio $\left(\mathrm{NH}_{4}{ }^{+}\right)$, por espectrofotometria de absorção molecular. Nas demais safras, a determinação dos nutrientes foi realizada seguindo metodologia descrita por TEDEsco et al. (1995). Para nitrogênio, as análises foram realizadas somente nas safras de 2001/2002 e 2002/2003. Ao considerar-se uma lâmina drenada de $0,10 \mathrm{~m}$ de profundidade, observa-se que as concentrações determinadas em $\mathrm{mg} \mathrm{L}^{-1}$, correspondem exatamente à quantidade de nutriente perdida em $\mathrm{kg} \mathrm{ha}^{-1}$.
Além dos nutrientes contidos na água de drenagem inicial, foram avaliados na cultura do arroz irrigado os seguintes parâmetros: produtividade, acamamento de plantas, esterilidade de espiguetas, grãos por panícula e massa de mil grãos. Para a avaliação do acamamento foram consideradas as seguintes classes: [0] 0\% de acamamento; [1] 1\% a 20\% de acamamento; [2] $21 \%$ a $40 \%$ de acamamento; [3] $41 \%$ a $60 \%$ de acamamento; [4] 61\% a $80 \%$ de acamamento e [5] $81 \%$ a $100 \%$ de acamamento. Por ocasião da colheita, realizou-se a observação visual na área das parcelas experimentais, relacionando a porcentagem de plantas acamadas com a classe correspondente.

Os dados obtidos nos experimentos foram submetidos à análise conjunta e as médias comparadas pelo teste de Tukey em nível de 5\% de probabilidade de erro. Os resultados expressos em porcentagem foram transformados para arco seno por ocasião da análise.

\section{RESULTADOS E DISCUSSÃO}

As quantidades de fósforo e nitrogênio retiradas do sistema juntamente com a água da drenagem inicial não foram influenciadas pelo momento ou modo de aplicação dos fertilizantes, sendo quantificado na média dos quatro anos de estudo, 0,07 e 0,81 $\mathrm{mg} \mathrm{L}^{-1}$ de fósforo e nitrogênio respectivamente (Tabela 1 ). Para esses nutrientes e considerando-se as normativas vigentes, as quantidades determinadas na água, em todos os anos de estudo, encontram-se abaixo dos níveis máximos permitidos pela Portaria n. ${ }^{\circ}$ 05, de 1989 da Secretaria de Saúde e do Meio Ambiente (SSMA, 1989), que limita em 1 e $10 \mathrm{mg} \mathrm{L}^{-1}$ respectivamente, a concentração de fósforo e nitrogênio total para efluentes líquidos que, possivelmente, sejam lançados em corpos d'água. Por outro lado, os resultados encontrados para fósforo, na média das safras de 2000/ 2001 e 2001/2002, situamse acima do estabelecido pela resolução n. ${ }^{\circ} 357$ do ConAma (2005). Segundo essa resolução, os teores de fósforo não deveriam ser superiores a $0,025 \mathrm{mg} \mathrm{L}^{-1}$.

Nos Estados Unidos, a Agência de Proteção Ambiental estabeleceu recentemente níveis recomendados de fósforo e nitrogênio total, para cada uma das regiões em que o país foi dividido, buscando reduzir problemas com excesso de nutrientes em corpos de água e fazendo inclusive distinções com relação ao tipo de manancial. Dessa forma, os critérios são variáveis, pois consideram as particularidades de cada região, sendo utilizados não somente para regulamentar, mas também para guiar os Estados, sendo ponto de partida para os padrões de qualidade da água (EpA, 2004). 
Para as condições norte-americanas, os valores recomendados para os distintos mananciais e nas diferentes regiões não devem exceder $0,128 \mathrm{mg}$ $\mathrm{L}^{-1}$ para fósforo e $2,18 \mathrm{mg} \mathrm{L}^{-1}$ para nitrogênio, sendo na maioria dos casos menores aos observados na água de drenagem do presente experimento. Assim justificase a preocupação de identificar manejos que proporcionem menores perdas de nutrientes do sistema produtivo para os mananciais hídricos.

Para potássio, observa-se que, na média dos quatros anos, menor quantidade foi carreada juntamente com a água da drenagem inicial naqueles tratamentos em que a adubação de base foi realizada aos 10 e 30 dias após a semeadura, bem como no tratamento-testemunha, indicando perdas maiores caso o potássio esteja dissolvido ou em suspensão no momento da retirada da água. Uma medida plausível para reduzir a saída de potássio do sistema, quando da realização da drenagem inicial, pode ser a aplicação dos fertilizantes potássicos posteriormente à implantação da cultura. Ainda para potássio, não se observaram diferenças para a perda de nutrientes via água de drenagem, entre os manejos de adubação realizados anteriormente à semeadura, estando os teores entre $3,16 \mathrm{a} 4,05 \mathrm{mg}$ $\mathrm{L}^{-1}$ de potássio. Em contrapartida, nos tratamentos cuja adubação foi realizada posteriormente à semeadura ou mesmo não foi executada (testemunha), as concentrações de potássio na água situaram-se entre 2,34 e $2,54 \mathrm{mg} \mathrm{L}^{-1}$, quantidades significativamente menores.

Tabela 1. Concentração de fósforo, potássio e nitrogênio na água de drenagem inicial, proporcionais às perdas de nutrientes, nos distintos manejos da adubação de base no sistema pré-germinado de arroz irrigado

\begin{tabular}{|c|c|c|c|c|c|c|c|c|}
\hline \multirow{2}{*}{ Safras } & \multicolumn{7}{|c|}{ Manejo dos fertilizantes fosfatados e potássicos $\left({ }^{1}\right)$} & \multirow{2}{*}{ Média $\left({ }^{2}\right)$} \\
\hline & $\mathrm{T} 1$ & $\mathrm{~T} 2$ & $\mathrm{~T} 3$ & $\mathrm{~T} 4$ & T5 & T6 & $\mathrm{T} 7$ & \\
\hline & \multicolumn{8}{|c|}{ Fósforo (mg L-1) $\left({ }^{3}\right)$} \\
\hline $2000 / 01$ & 0,10 & 0,10 & 0,10 & 0,10 & 0,10 & 0,10 & 0,10 & $0,10 \mathrm{~B}$ \\
\hline $2001 / 02$ & 0,24 & 0,12 & 0,12 & 0,21 & 0,12 & 0,22 & 0,10 & $0,16 \mathrm{~A}$ \\
\hline $2002 / 03$ & 0,02 & 0,01 & 0,02 & 0,01 & 0,00 & 0,01 & 0,00 & 0,01 D \\
\hline $2003 / 04$ & 0,02 & 0,01 & 0,03 & 0,01 & 0,01 & 0,01 & 0,01 & $0,02 \mathrm{C}$ \\
\hline Média & 0,09 & 0,06 & 0,07 & 0,08 & 0,06 & 0,09 & 0,05 & 0,07 \\
\hline
\end{tabular}

C.V. $=37,6$

\begin{tabular}{|c|c|c|c|c|c|c|c|c|}
\hline \multirow[b]{2}{*}{$2000 / 01$} & \multicolumn{8}{|c|}{ Potássio $\left(\mathrm{mg} \mathrm{L}^{-1}\right)$} \\
\hline & 3,65 & 3,65 & 5,70 & 4,70 & 2,85 & 2,85 & 3,35 & $3,82 \mathrm{~A}$ \\
\hline $2001 / 02$ & 2,90 & 2,85 & 2,95 & 3,05 & 2,65 & 2,50 & 1,40 & $2,61 \mathrm{~B}$ \\
\hline $2002 / 03$ & 3,03 & 2,47 & 2,74 & 3,51 & 1,07 & 1,56 & 1,58 & $2,28 \mathrm{~B}$ \\
\hline $2003 / 04$ & 4,20 & 3,70 & 3,90 & 4,90 & 2,80 & 3,25 & 3,05 & $3,68 \mathrm{~A}$ \\
\hline Média & $3,44 \mathrm{a}$ & $3,16 \mathrm{ab}$ & $3,82 \mathrm{a}$ & $4,05 \mathrm{a}$ & $2,34 \mathrm{~b}$ & $2,54 \mathrm{~b}$ & $2,34 \mathrm{~b}$ & 3,10 \\
\hline \multirow[t]{2}{*}{$\mathrm{C} . \mathrm{V} .=$} & 34,7 & & & & & & & \\
\hline & \multicolumn{8}{|c|}{ Nitrogênio $\left(\mathrm{mg} \mathrm{L}^{-1}\right)$} \\
\hline $2000 / 01$ & - & - & - & - & - & - & - & - \\
\hline $2001 / 02$ & 1,45 & 1,78 & 1,53 & 1,13 & 1,04 & 1,91 & 2,01 & $1,55 \mathrm{~A}$ \\
\hline $2002 / 03$ & 0,07 & 0,04 & 0,09 & 0,05 & 0,07 & 0,07 & 0,07 & $0,07 \mathrm{~B}$ \\
\hline $2003 / 04$ & - & - & - & - & - & - & - & - \\
\hline Média & 0,76 & 0,92 & 0,81 & 0,59 & 0,56 & 0,99 & 1,04 & 0,81 \\
\hline$C . V .=$ & 81,4 & & & & & & & \\
\hline
\end{tabular}

$\left({ }^{1}\right)$ [T1] aplicação dos fertilizantes fosfatados e potássicos 20 dias antes da semeadura (DAS) e incorporação ao solo. [T2] aplicação dos fertilizantes 20 DAS, sem incorporação. [T3] aplicação dos fertilizantes 5 DAS e incorporação ao solo. [T4] aplicação dos fertilizantes 5 DAS, sem incorporação. [T5] aplicação dos fertilizantes à lanço 10 dias após a semeadura. [T6] aplicação dos fertilizantes à lanço 30 dias após a semeadura e [T7]: testemunha sem aplicação dos fertilizantes potássicos e fosfatados.

$\left({ }^{2}\right)$ Médias seguidas pela mesma letra maiúscula não diferem na coluna pelo teste de Tukey a $5 \%$ de probabilidade; e minúscula, na linha.

$\left({ }^{3}\right)$ Ao considerar-se uma lâmina drenada de $0,10 \mathrm{~m}$ de profundidade, observa-se que as concentrações determinadas em mg $\mathrm{L}^{-1}$, correspondem exatamente à quantidade de nutriente perdida em $\mathrm{kg} \mathrm{ha}^{-1}$.

- Dados não processados. 
Autores como Weber et al. (2003) demonstram que as perdas podem afetar a sustentabilidade da atividade e também relatam a necessidade de reduzilas com a utilização de maior período de tempo entre adubação/preparo final do solo e a drenagem subseqüente. Cabe salientar que o preparo da área foi realizado com solo não-inundado. Nessa condição, pequena quantidade de solo entra em suspensão na lâmina de água, condicionando menor perda de nutrientes. Possivelmente, se o preparo da área fosse realizado com lâmina de água, existiriam mais sólidos em suspensão na água e as perdas de nutrientes seriam maiores do que os valores observados. De qualquer forma, a saída de água dos quadros, independentemente do momento e modo de execução da adubação de base, propicia a retirada de nutrientes do sistema, que por menores que sejam, podem provocar, a longo prazo, o empobrecimento do solo e a contaminação dos mananciais hídricos. Mesmo nos tratamentos que não receberam adubação, verificaramse perdas de nitrogênio, fósforo e potássio através da água removida, evidenciando-se com isso, que se deve buscar a combinação de manejos de água e adubação que permitam a produção sustentável de arroz. Essas perdas também podem ser evitadas, pelo manejo da água de irrigação, com manutenção de lâmina contínua, desde a inundação da área (MARCHEZAN et al., 2004). As variações observadas entre as safras com relação à perda de nutrientes (Tabela 1), além das influências ambientais de cada ano, podem estar associadas aos métodos de quantificação, especialmente para fósforo e nitrogênio na safra de 2002/2003.

Os manejos de adubação testados, na média dos quatro anos, não influenciaram os parâmetros avaliados na cultura do arroz irrigado (Tabela 2). Com relação à produtividade, obteve-se média de $6960 \mathrm{~kg}$ $\mathrm{ha}^{-1}$, havendo variações entre $4594 \mathrm{~kg} \mathrm{ha}^{-1}$, na safra com menor produtividade até $9516 \mathrm{~kg} \mathrm{ha}^{-1}$ na mais produtiva. Os resultados sugerem a realização da adubação de base no sistema pré-germinado após a semeadura e/ou o estabelecimento da cultura, especialmente com relação ao potássio, a fim de reduzir a saída desse nutriente quando da drenagem inicial. Ademais, a realização da adubação de base, aliada à elevação da temperatura, propiciam condições favoráveis ao desenvolvimento de algas (DiAz-Pulido e МсСоок, 2005), que dificultam o estabelecimento das plântulas, especialmente quando ocorrem antes de ser efetuada a semeadura ou na fase inicial de desenvolvimento da cultura.

Assim, propõem-se a execução da adubação de base juntamente com a primeira adubação nitrogenada de cobertura, buscando reduzir custos.
Por outro lado, verificou-se que as quantidades de fósforo e potássio fornecidas, não elevaram os níveis de produtividade, uma vez que o tratamentotestemunha obteve comportamento semelhante àqueles com utilização da adubação. Da mesma forma, MACHADO e FrANCO (1995), avaliando a eficiência do parcelamento da adubação potássica para com a produtividade do arroz irrigado cultivado no sistema pré-germinado, não observaram incremento de produtividade com a utilização deste nutriente. CAstilhos et al. (2002), buscando explicar a ausência de resposta à adubação potássica pela cultura do arroz irrigado, estudaram a contribuição da mineralogia como fonte potencial deste nutriente e identificaram minerais primários e secundários que contêm potássio e podem disponibilizá-lo. Ainda, CAstilhos e Meurer (2002), avaliando o suprimento de $\mathrm{K}$ em solos cultivados com arroz irrigado por alagamento, concluem que o K trocável não é a única forma do elemento no solo capaz de nutrir as plantas, havendo contribuição de formas de $\mathrm{K}$ não trocável, que podem explicar a falta de resposta a esse nutriente em experimentos de campo.

Para fósforo, quando um solo é submerso e as condições de redução são estabelecidas, ocorre aumento da sua concentração na água, bem como na sua disponibilidade, o que talvez explique a baixa ou, até mesmo, a falta de resposta do arroz irrigado à aplicação desse nutriente ao solo (GuILHERME et al. 2000), conforme observado para os níveis de produtividade do presente trabalho (Tabela 2).

Notadamente, observam-se variações nos parâmetros produtivos no decorrer das safras, que estão fortemente atreladas às condições climáticas. Na safra de 2002/2003, ocorreram dois temporais no fim de fevereiro, com alta intensidade de chuvas e ventos de até $120 \mathrm{~km} \mathrm{~h}^{-1}$, que provocaram o acamamento de plantas e reflexos negativos à produtividade, apesar dos valores obtidos $(7095 \mathrm{~kg}$ $\mathrm{ha}^{-1}$ ). Além disso, observou-se na média do experimento, $19,3 \%$ de espiguetas estéreis, sendo esse valor o mais elevado entre os anos de estudo. $\mathrm{Na}$ safra de 2001/2002, a ocorrência de acamamento foi decisiva para a obtenção da menor produtividade entre os anos de estudo, ocasião em que mais de $61 \%$ das plantas acamaram, comprometendo inclusive o pleno enchimento dos grãos. Em contrapartida, na safra de 2003/2004 obteve-se a maior produtividade, sendo esta decorrente de fatores climáticos favoráveis, tais como: elevada radiação e ausência de temperaturas baixas nas fases críticas de cultura, que propiciaram elevado número de grãos por panícula, reduzida esterilidade de espiguetas e excelente enchimento dos grãos. 
Tabela 2. Produtividade, grãos por panícula, esterilidade de espiguetas, massa de mil grãos e de classes de acamamento, para os manejos da adubação de base no sistema pré-germinado de arroz irrigado

\begin{tabular}{|c|c|c|c|c|c|c|c|c|}
\hline \multirow{2}{*}{ Safras } & \multicolumn{7}{|c|}{ Manejo dos fertilizantes fosfatados e potássicos $\left({ }^{1}\right)$} & \multirow{2}{*}{ Média $\left({ }^{2}\right)$} \\
\hline & $\mathrm{T} 1$ & $\mathrm{~T} 2$ & $\mathrm{~T} 3$ & $\mathrm{~T} 4$ & T5 & T6 & $\mathrm{T} 7$ & \\
\hline \multicolumn{9}{|c|}{ Produtividade $\left(\mathrm{kg} \mathrm{ha}^{-1}\right)$} \\
\hline 2000/01 & 6738 & 6694 & 6790 & 6694 & 6787 & 6573 & 6180 & $6637 \mathrm{C}$ \\
\hline $2001 / 02$ & 4158 & 4082 & 4511 & 4506 & 4811 & 5338 & 4751 & $4594 \mathrm{D}$ \\
\hline $2002 / 03$ & 7428 & 7182 & 6948 & 7462 & 6964 & 7015 & 6666 & 7095 B \\
\hline 2003/04 & 9205 & 9686 & 9906 & 9745 & 9582 & 9245 & 9241 & $9516 \mathrm{~A}$ \\
\hline Média & $6822^{\text {ns }}$ & 6911 & 7039 & 7102 & 7036 & 7042 & 6709 & 6960 \\
\hline C.V. $=$ & 8,9 & & & & & & & \\
\hline \multicolumn{9}{|c|}{ N. ${ }^{\circ}$ de grãos por panícula } \\
\hline $2000 / 01$ & 67 & 68 & 57 & 57 & 79 & 64 & 58 & $64 \mathrm{C}$ \\
\hline $2001 / 02$ & 89 & 92 & 85 & 84 & 90 & 85 & 82 & $87 \mathrm{AB}$ \\
\hline $2002 / 03$ & 85 & 78 & 78 & 82 & 72 & 81 & 82 & $80 \mathrm{~B}$ \\
\hline $2003 / 04$ & 88 & 94 & 86 & 95 & 87 & 91 & 93 & $91 \mathrm{~A}$ \\
\hline Média & $82^{\text {ns }}$ & 83 & 77 & 79 & 82 & 81 & 78 & 80 \\
\hline C.V. $=$ & 12,9 & & & & & & & \\
\hline \multicolumn{9}{|c|}{ Esterilidade de espiguetas (\%) } \\
\hline $2000 / 01$ & 20,0 & 16,0 & 16,3 & 16,8 & 16,8 & 19,3 & 19,3 & $17,8 \mathrm{~A}$ \\
\hline $2001 / 02$ & 17,2 & 16,0 & 14,2 & 13,0 & 13,2 & 15,2 & 14,0 & $14,7 \mathrm{~B}$ \\
\hline $2002 / 03$ & 18,5 & 20,5 & 18,7 & 20,5 & 17,7 & 22,0 & 17,5 & $19,3 \mathrm{~A}$ \\
\hline $2003 / 04$ & 15,7 & 12,7 & 11,2 & 14,0 & 13,0 & 15,7 & 15,7 & $14,0 \mathrm{~B}$ \\
\hline Média & $17,9^{\text {ns }}$ & 16,3 & 15,1 & 16,1 & 15,2 & 18,1 & 16,6 & 16,5 \\
\hline $\mathrm{C} . \mathrm{V} .=$ & 23,0 & & & & & & & \\
\hline \multicolumn{9}{|c|}{ Massa de mil grãos (g) } \\
\hline $2000 / 01$ & 26,5 & 26,3 & 25,8 & 26,0 & 26,3 & 24,8 & 26,0 & $25,9 \mathrm{~B}$ \\
\hline 2001/02 & 24,0 & 24,5 & 23,5 & 24,2 & 24,2 & 24,0 & 24,5 & $24,1 \mathrm{~B}$ \\
\hline $2002 / 03$ & 25,7 & 25,7 & 25,7 & 25,2 & 25,2 & 26,0 & 25,0 & $25,5 \mathrm{~B}$ \\
\hline $2003 / 04$ & 28,0 & 29,2 & 27,0 & 27,2 & 28,0 & 28,0 & 28,2 & $27,9 \mathrm{~A}$ \\
\hline Média & $26,1^{\text {ns }}$ & 26,4 & 25,5 & 25,7 & 25,9 & 25,7 & 25,9 & 25,9 \\
\hline C.V. $=$ & 8,9 & & & & & & & \\
\hline \multicolumn{9}{|c|}{ Classes de acamamento } \\
\hline $2000 / 01$ & 0 & 0 & 0 & 0 & 0 & 0 & 0 & 0 \\
\hline $2001 / 02$ & 4 & 4 & 4 & 4 & 4 & 4 & 4 & 4 \\
\hline $2002 / 03$ & 5 & 4 & 5 & 4 & 5 & 3 & 5 & 4 \\
\hline $2003 / 04$ & 0 & 0 & 0 & 0 & 0 & 0 & 0 & 0 \\
\hline
\end{tabular}

(1) [T1] aplicação dos fertilizantes fosfatados e potássicos 20 dias antes da semeadura (DAS) e incorporação ao solo. [T2] aplicação dos fertilizantes 20 DAS, sem incorporação. [T3] aplicação dos fertilizantes 5 DAS e incorporação ao solo. [T4] aplicação dos fertilizantes 5 DAS, sem incorporação. [T5] aplicação dos fertilizantes à lanço 10 dias após a semeadura. [T6] aplicação dos fertilizantes à lanço 30 dias após a semeadura e [T7]: testemunha sem aplicação dos fertilizantes potássicos e fosfatados.

$\left({ }^{2}\right)$ Médias seguidas pela mesma letra na coluna não diferem entre si pelo teste de Tukey a $5 \%$ de probabilidade, na comparação entre as safras.

$\left({ }^{\text {ns }}\right)$ Teste F não significativo a 5\% de probabilidade. 


\section{CONCLUSÕES}

1. A drenagem inicial no sistema prégerminado de arroz irrigado proporciona perda de fósforo, potássio e nitrogênio, independentemente do momento da aplicação e da incorporação ou não da adubação de base.

2. As perdas de potássio são influenciadas pelo manejo da adubação, sendo menores quando a adubação é realizada após a semeadura da cultura.

3. A produtividade do arroz irrigado não é influenciada pelo momento e modo de realização da adubação fosfatada e potássica, porém a aplicação de fósforo e potássio deve ser executada após a drenagem inicial, a fim de reduzir as perdas de potássio.

\section{AGRADECIMENTOS}

Os autores agradecem aos demais integrantes do Grupo de Pesquisa em Arroz e Uso Alternativo de Várzea pela assistência durante os anos de realização do experimento, bem como ao Conselho Nacional de Desenvolvimento Científico e Tecnológico (CNPq) pelas bolsas de estudo concedidas e pelo suporte financeiro.

Os autores agradecem também ao Engenheiro Agrônomo Leandro Homrich Lorentz, pelo auxílio despendido na realização das análises estatísticas.

\section{REFERÊNCIAS}

BELTRAME, L.F.S.; IOCHPE, B.; ROSA, S.M. da; MIRANDA, T.L.G. de. Lixiviação de íons em solo cultivado com arroz irrigado por inundação. Revista Brasileira de Ciência do Solo, Viçosa, v.16, p. 203-208. 1992.

CASTILHOS, R.M.; MEURER, E.J.; KÄMPF, N.; PINTO, L.F.S. Mineralogia e fontes de potássio em solo no Rio Grande do Sul cultivados com arroz irrigado. Revista Brasileira de Ciência do Solo, Viçosa, v.26, p.579-587, 2002.

CASTILHOS, R.M.V.; MEURER, E.J. Suprimento de potássio de solo do Rio Grande do Sul para arroz irrigado por alagamento. Revista Brasileira de Ciência do Solo, Viçosa, v.26, p.977-982, 2002.

CHEUNG, K.C.; POON, B.H.T; LAN, C.Y.; WONG, M.H. Assessment of metal and nutrient concentrations in river water and sediment collected from the cities in the Pearl River Delta, South China. Chemosphere, v. 52, p.1431-1440. 2003.

CONAMA, Conselho Nacional de Meio Ambiente. Resolução CONAMA n. ${ }^{\circ}$ 357, de 17 de março de 2005. 23p.
DIAZ-PULIDO, G.; MCCOOK, L.J. Effects of nutrient enhancement on the fecundity of a coral reef macroalga. Journal of Experimental Marine Biology and Ecology, Groton, v. 317, p. 13-24. 2005.

DIVADE, V.; PARDOS, M.; DISERENS, J.; UGAZIO, G.; THOMAS, R.; DOMINIK, J. Characterisation of bed sediments and suspension of the river Po (Italy) during normal and high flow conditions. Water Research, Lyngby, v. 37, p. 28472864. 2003.

EPA, Environmental Protection Agency. Clean Water Act. Water Science. Water Quality Criteria. Nutrients. Disponível em: <http://www.epa.gov/waterscience/criteria> Acesso em: 03 de dezembro de 2004.

GUILHERME, L.R.G.; CURI, N.; SILVA, M.L.N.; RENÓ, N.B.; MACHADO, R.A.F. Adsorção de fósforo em solo de várzea do Estado de Minas Gerais. Revista Brasileira de Ciência do Solo, Viçosa, v.24, p.27-34, 2000.

HERNÁNEZ, J.; MEURER. E.J. Disponibilidade de fósforo em seis solos do Uruguai afetada pela variação temporal das condições de oxirredução. Revista Brasileira de Ciência do Solo, Viçosa, v.24, p.19-26, 2000.

MACHADO, M.O.; FRANCO, J.C.B. Parcelamento da adubação potássica em arroz pré-germinado, no solo Pelotas (Planossolo). In: REUNIÃO DA CULTURA DO ARROZ IRRIGADO, 21, 1995. Porto Alegre, RS. Anais... Porto Alegre: Instituto Rio Grandense do Arroz, 1995. p.177-180.

MARCHEZAN, E.; CAMARGO, E.R.; LOPES, S.I.G.; MACHADO, F.M.; MICHELON, S. Desempenho de genótipos de arroz irrigado cultivados no sistema pré-germinado com inundação contínua. Ciência Rural, Santa Maria, v. 34, n.5, p.1349-1354. 2004.

MARCHEZAN, E.; MACHADO, S.L.O; RIGHES, A.A.;SANTOS, F.M.dos; SEGABINAZZI, T. Perda de nutrientes na água de drenagem inicial na cultura do arroz irrigado. In: CONGRESSO DA CADEIA PRODUTIVA DE ARROZ, 1; REUNIÃO NACIONAL DE PESQUISA DE ARROZ, 7, 2002. Florianópolis, SC. Anais... Santo Antônio de Goiás: Embrapa Arroz e Feijão, 2002. p.680-683.

MOLEN, D.T.V.D.; BREEUWSMA, A.; BOERS, P.C.M. Agriculture nutrient losses to surface water in Netherlands: impact, strategies, and perspectives. Journal Enviromental Quality, Madison, v. 27, p. 4-11. 1998.

SARPLEY, A.; FOY, B.; WITHERS, P. Practical and innovative measures for the control of agricultural phosphorus losses to water: an overview. Journal of Environmental Quality, Madison, v.29, n.1, p.1-9. 2000.

SILVA, L.S.da; SOUSA, R.O.de; BOHNEN, H. Alterações nos teores de nutrientes em dois solos alagados, com e sem plantas de arroz. Ciência Rural, Santa Maria, v. 33, n..3, p. 487-490. 2003. 
SSMA, Secretaria da Saúde e Meio Ambiente. Portaria n 05/ 89 de 16 de março de 1989. Aprova a Norma Técnica que dispõem sobre critérios e efluentes líquidos... Diário Oficial, Porto Alegre, 29 de março de 1989.

TEDESCO, M.J. GIANELLO, C.; BISSANI, C.A.; BOHNEN, H.; VOLKWEISS, S.J. Análises de solo, plantas e outros materiais. 2 ed. Porto Alegre: UFRGS, Faculdade de Agronomia, Departamento de Solos, 1995. 174p. (Boletim Técnico de Solos, 5)
WEBER, L.; MARCHEZAN, E.; CARLESSO, R.; MARZARI, V. Cultivares de arroz irrigado e nutrientes na água de drenagem em diferentes sistemas de cultivo. Ciência Rural, Santa Maria, v. 33, n.1, p. 27-33. 2003. 